\title{
EDITORIAL
}

\section{Should All Patients With Endometriosis Undergo Surgery?}

\author{
Tono Djuwantono
}

Not every endometriotic patients should undergo surgery; the treatment of this condition should be adjusted to the needs and age of the patients. Medical treatment should be administered to teenagers and unmarried patients, and it could be given to reduce pain and prevent recurrence. However, medical treatment cannot improve fertility problems, particularly to those who expect pregnancy. ${ }^{1}$

Surgical therapy is suitable for those expecting pregnancy. It not only reduces pain but also improves the microenvironment of adnexa and peritoneal, thereby increasing fertility. ${ }^{1,2}$ Based on our results, those with endometriosis who underwent laparoscopic surgery had the rate spontaneous pregnancy of $46.3 \%$ within a year after surgery. ${ }^{3}$ However, it should be noted that the recurrence rate increased within a year in the absence of pregnancy. ${ }^{1,4}$ Careful monitoring should be performed during the first year after surgery to increase the potency of fertility, and providing adjuvant hormonal therapy when necessary to reduce the risk of recurrence. ${ }^{4,5}$ Medical treatment should be given for those who do not expect pregnancy to prevent recurrence. ${ }^{6}$ However, if pregnancy is expected, assisted reproductive technology (ART) could be given immediately according to the patient problems. Any individual or clinic dealing with endometriosis surgery should estabilsh risk management for recurrence since recurrence may worsen the fertility prognosis. The combination of surgical and adjuvant hormonal therapy is recommended before ART for endometriosis patients with AFS III/IV accompanied by complications such as hydrosalpinx, adhesion, and adenomyosis in order to improve the outcome of IVF.7 Any individual or clinic treating endometriosis should expand the paradigm "performed endometriosis surgery, dare to prevent recurrence" and "performed endometriosis surgery, dare to increase reproductive potential".

\section{References}

1. Kaur KK, Allahbadia G. An Update on Pathophysiology and Medical Management of Endometriosis. Advances Reprod Scienc. 2016; 4: 53-73.

2. Singh SS, Suen MW. Surgery for endometriosis: beyond medical therapies. Fertil Steril. 2017; 107(3): 549-54.

3. Tjandraprawira KD, Djuwantono T. Postlaparoscopic GnRH agonist Therapy does not Improve Spontaneous Conception Rates of Women with Endometriosis. Indones J Obstet Gynecol. 2017; 5(2): 87-93.

4. Kikuchi I, Takeuchi H, Kitade M, Shimanuki H, Kumakiri J, Kinoshita K. Recurrence rate of endometriomas following a laparoscopic cystectomy. Acta Obstet Gynecol Scandinavica. 2006; 85(9): 1120-4.

5. Muzii L, Marana R, Caruana P, Catalano GF, Margutti F, Panici PB. Postoperative administration of monophasic combined oral contraceptives after laparoscopic treatment of ovarian endometriomas: a prospective, randomized trial. Am J Obstet Gynecol. 2000; 183(3): 588-92.

6. Ota Y, Andou M, Yanai S, Nakajima S, Fukuda M, Takano M, dkk. Long-term administration of dienogest reduces recurrence after excision of endometrioma. J Endomet Pelvic Pain Disorders. 2015; 7(2): 63-7.

7. Johnson N, van Voorst S, Sowter MC, Strandell A, Mol BW. Surgical treatment for tubal disease in women due to undergo in vitro fertilisation. The Cochrane database of systematic reviews. 2010(1): CD002125. 